\title{
Urban Type Classification and Characteristic Analysis through Time-Series Environmental Changes for Land Use Management for 31 Satellite Cities around Seoul, South Korea
}

\author{
Jin-Hyo Kim ${ }^{1}$, Oh-Sung Kwon ${ }^{2, *} \mathbb{1}$ and Jung-Hwa Ra ${ }^{3}$ \\ 1 Division of Forestland Spatial Planning, Korea Forest Conservation Association, Daejeon 35262, Korea; \\ gsjhk@kfca.re.kr \\ 2 Department of Ecology and Environment, Gyeonggi Research Institute, Suwon 16207, Korea \\ 3 Department of Landscape Architecture, Kyungpook National University, Daegu 41566, Korea; jhra@knu.ac.kr \\ * Correspondence: kos8282@gri.re.kr; Tel.: +82-31-250-3252
}

Citation: Kim, J.-H.; Kwon, O.-S.; Ra, J.-H. Urban Type Classification and Characteristic Analysis through Time-Series Environmental Changes for Land Use Management for 31 Satellite Cities around Seoul, South Korea. Land 2021, 10, 799. https:// doi.org/10.3390/land10080799

Academic Editor: Giuseppe Pulighe

Received: 29 June 2021

Accepted: 27 July 2021

Published: 29 July 2021

Publisher's Note: MDPI stays neutral with regard to jurisdictional claims in published maps and institutional affiliations.

Copyright: (c) 2021 by the authors. Licensee MDPI, Basel, Switzerland. This article is an open access article distributed under the terms and conditions of the Creative Commons Attribution (CC BY) license (https:/ / creativecommons.org/licenses/by/ $4.0 /)$.

\begin{abstract}
The objective of the present study was to determine changes in land coverage for 31 satellite cities surrounding Seoul and changes in values of MSPA (Morphological Spatial Pattern Analysis) for a time period of about 30 years (from 1988 to 2018). Cities that showed similar environmental changes were grouped utilizing a hierarchical cluster analysis. The results of this study are summarized as follows: First, as a result of analyzing changes in land coverage, urbanized areas in all 31 cities greatly increased, whereas areas of forest, grassland, farmland, wetland, etc., greatly decreased. Second, as a result of carrying out MSPA for green areas in each city, the number of Cores, Islets as stepping-stone green areas, and Branches greatly decreased. As a result of analyzing factors in cluster analysis, 12 variables were classified into four groups. After performing a cluster analysis, the 31 cities were classified into six clusters. Cluster- 6 showed the biggest decrease in wetland areas. These results could be used as basic data for establishing differentiated environmental policies for clusters of cities that show similar environmental changes, and for establishing policy priorities that break away from uniform environmental policies at the local level.
\end{abstract}

Keywords: land-cover change; MSPA; cluster analysis; land use management

\section{Introduction}

Korea has achieved economic growth at a very high speed since the 1960s. Rapid urbanization and industrialization has particularly progressed around Seoul, the capital of Korea. As the traffic congestion problem in Seoul became severe in the late 1970s, a suburbanization phenomenon involving population movements into Gyeonggi-do, the outskirts of Seoul, quickly emerged to mitigate this problem [1-3]. As a result, the capital area including Seoul and Gyeonggi-do formed a typical metropolitan area. About 26 million people, close to half of the Korean population, live in this capital area.

Although this rapid growth of the city has been accompanied by changes in various aspects such as the natural environment and the human environment, it has had direct effects on the natural environment in particular. Environmental damage in the capital area is intensifying day by day. Such environment damage is occurring across Korea and all over the world. As numerous development plans are damaging the natural environment at an irrevocable level, efforts have been made to solve environmental problems in various aspects.

First, in relation to basic studies, European countries such as Germany, Italy, etc., where environmental damage is intensifying, have conducted studies based on landscape ecology, and many efforts have been made to create sustainable land environments by grafting diverse theories into actual land plans [4-7]. Similar studies are also actively conducted in North American countries such as the USA [8-11]. For example, Forman has arranged a theoretical basis for North American landscape ecological planning based on a landscape ecology [12]. 
Moreover, data about environmental changes (in land use and land coverage) can now be collected and analyzed within a short period of time thanks to the development of diverse technologies such as Geographic Information System (GIS) and Remote Sensing (RS) technology [13-18]. In particular, FRAGSTATS, a spatial pattern analysis program developed by McGarigal and Marks [19], is a core tool that can quantitatively determine structural patterns and change aspects of landscape elements. Utilizing FRAGSTATS, various studies have been actively conducted all over the world [20-23]. For example, Reddy et al. [24] investigated the effect of forest fragmentation in India by utilizing landscape indices such as Mean Patch Size (MPS) and Edge Density (ED).

In legal and institutional aspects, efforts have been steadily made to cope with environmental changes in accordance with "Sustainable Development", which has been widely used after the announcement of the Bryndtkand report of WCED in 1987 and the "Paris Climate Agreement" adopted in the UN Weather Change Conference in 2015. Korea is working on an interlocking between land plans and environmental plans based on Article 5 (Environment-friendly Land Management) of the Framework Act on the National Land, and the Framework Act on Environmental Policy (Responsibilities of the State and Local Governments). The objective of such an interlocking plan is to sustainably upbuild the land by minimizing the effect on the environment at a plan level in advance [25-27].

Considering that development plans are direct causes of environmental problems that take place mostly in cities, establishing environmental policies at a city level has a very important meaning. However, it may be more effective to solve housing problems, traffic problems, and, in particular, environmental problems caused by urban expansion by comprehensively bundling up several cities together rather than solving these problems within individual cities. Thus, it is necessary to create a new spatial unit that bundles up cities that show similar environmental changes that transcend the boundaries of administrative districts.

In relation to this, studies that group cities showing similar characteristics have been actively conducted through cluster analyses [28-33]. Targeting about 280 villages where mountain village development programs have been carried out, Ko et al. [34] categorized villages showing similar mountain village scenery by utilizing the altitude, forest ratio, farmland ratio, coniferous forest ratio, broadleaf forest ratio, and ecological and natural map rating ratios. Further, Kuo et al. [35] classified the impact of urban development on the natural environment into six clusters for Tainan, Taiwan. Based on this, an evaluation methodology was established to simulate and analyze the impact of urban growth.

Although diverse efforts have been made to solve environmental problems, as mentioned earlier, precedent studies have the following limitations: First, studies that utilized FRAGSTATS did not present analysis results as drawings. They had limitations in that it was difficult to correlate their results with drawings of development plans. Additionally, with respect to cluster analyses, cities were categorized by considering various aspects such as social and economic issues, transportation, land cover change, MSPA structure, water supply and demand, surface temperature, and surface runoff. Among the various factors for colonization, MSPA has been limitedly used mainly for studies related to eco-corridors such as wildlife passageways. In other words, there have been relatively few studies examining changes in MSPA values and diagnosing environmental problems based on the changes in green areas for each cluster due to urbanization.

Accordingly, in the present study, we categorized 31 cities in Gyeonggi-do adjacent to Seoul at a regional level based on results of time-sequential environmental changes to grasp characteristics of environmental changes by type. We believe that the results of the present study could be used as basic data for establishing differentiated environmental plans for cities with similarities or for establishing environmental policy priorities, breaking away from standardized policies related to the environment that appear at the regional level in particular. 


\section{Data and Methods}

\subsection{Research Area}

The present study was conducted for 31 satellite cities in Gyeonggi-do adjacent to Seoul, the capital of Korea (Figure 1). The main status of each city is shown as follows. First, the city with the biggest area among these 31 cities was found to be Yangpyeong $\left(877.8 \mathrm{~km}^{2}\right)$, followed by Gapyeong and Pocheon. We could see that Gwacheon, Gwangmyeong, and Gunpo were much smaller in size than the other cities. Looking at the number of populations by city, Suwon, Goyang, Yongin, Seongnam, and Hwaseong had the largest population in that order. On the other hand, Yeoncheon, Gwacheon, Gapyeong, and Dongducheon have low population numbers. In particular, Yeoncheon has about 44,000 people, showing the lowest population among all 31 cities. In addition, when we looked into the geographical characteristics of each city, Yeoncheon and Paju were playing an important role militarily as they are close to North Korea. Goyang, Seongnam, Bucheon, and Hanam were under high development pressure in the past as they were directly in contact with Seoul. Such development pressure still exists today. The area, population, and location characteristics of the 31 cities are presented in Appendix A.

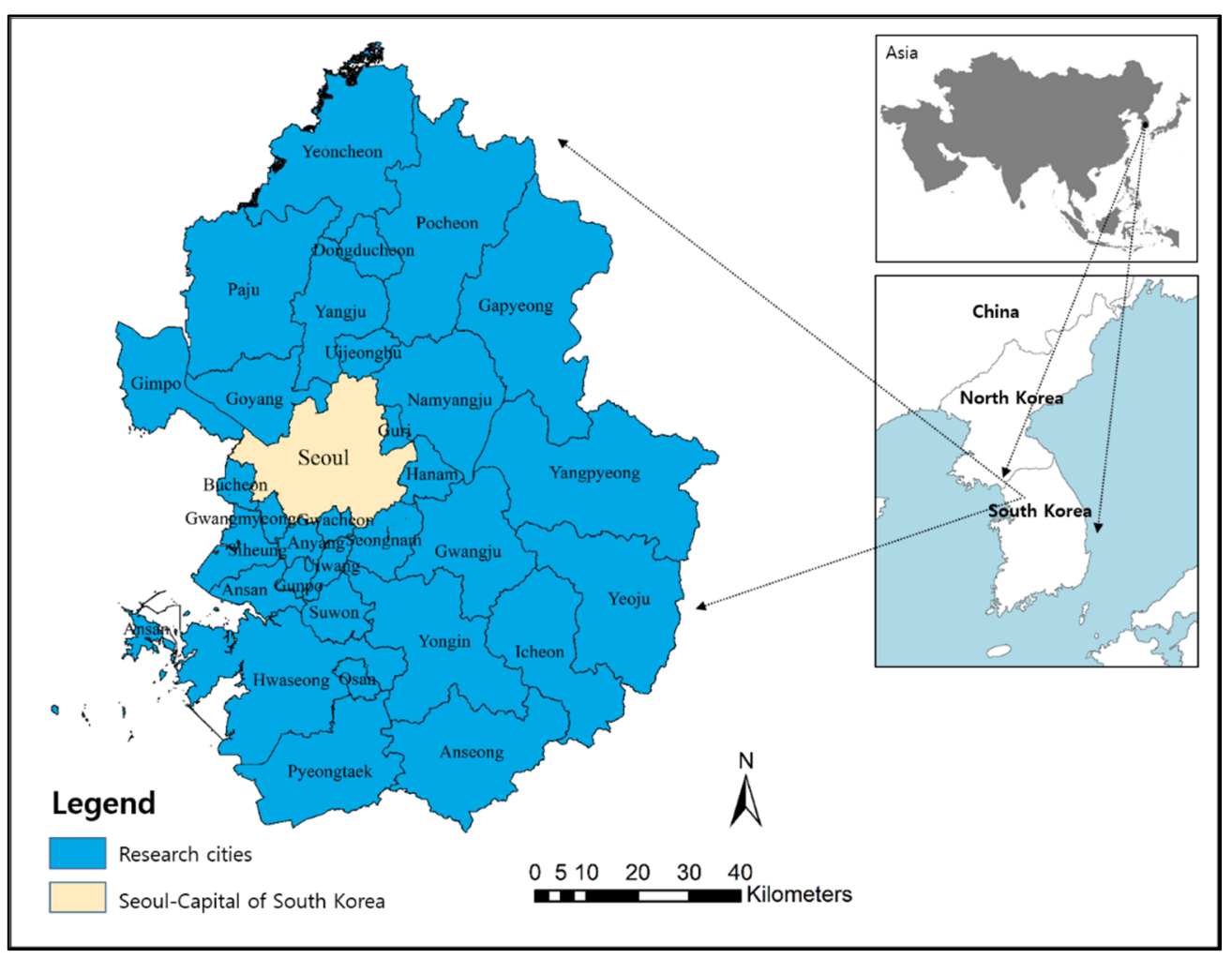

Figure 1. Location of research cities.

\subsection{Procedure for Conductiong the Study}

The procedure for conducting the present study is largely divided into three stages (Figure 2). First, an analysis of changes in land coverage for each of the 31 cities was performed based on land cover maps of 1988 and 2018. Second, an MSPA was performed for structural changes in each of the 31 cities. Third, a cluster analysis was performed to grasp the characteristics of each cluster. The detailed study method of each stage is shown below. 


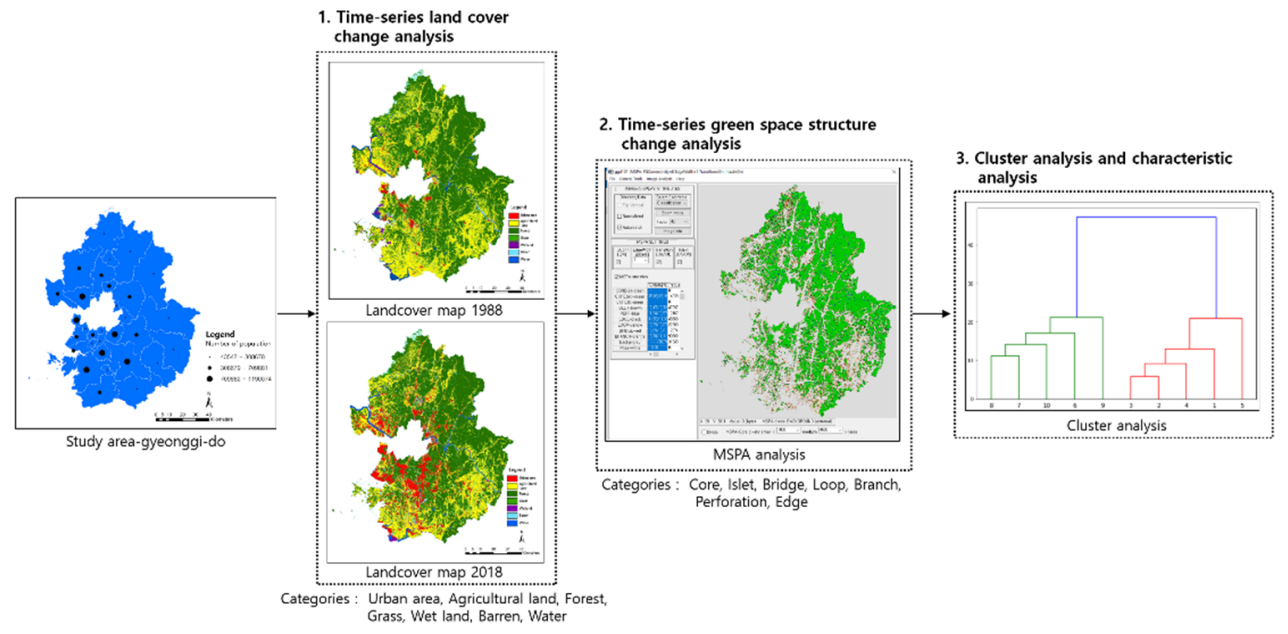

Figure 2. Research flow.

\subsection{Analysis of Changes in Landcover Change in Each City}

For the analysis of changes in the land coverage in each city, a Level I Land Cover Map provided by Environmental Geographic Information Service [36] was used. The major classification Level I Land Cover Map has been constructed every 10 years, starting in 1988. In this study, the most historical data, from 1988, and the most recent, from 2018, were used. The reason for this is that the first new town developments (Ilsan, Bundang, etc.) were carried out from 1989 to 1996, and the second new town developments (Seongnam, Hwaseong, etc.) were carried out from 2001 to 2017. In other words, out of the 31 cities, large-scale development plans were carried out for cities adjacent to Seoul until recently. Therefore, it was judged that the changes in land cover and the changes to MSPA structure according to the development plan for each city could be best understood if the data for 1988 and 2018 were used. A Level I Land Cover Map was divided into seven land cover types (urbanized areas, agricultural areas, forest areas, grassland, wetland, bare land, and waters). It was prepared based on a resolution of $30 \mathrm{~m} \times 30 \mathrm{~m}$. Changes in land coverage for each city were examined based on such land cover maps. Land cover maps utilized in the present study are as follows (Figure 3).

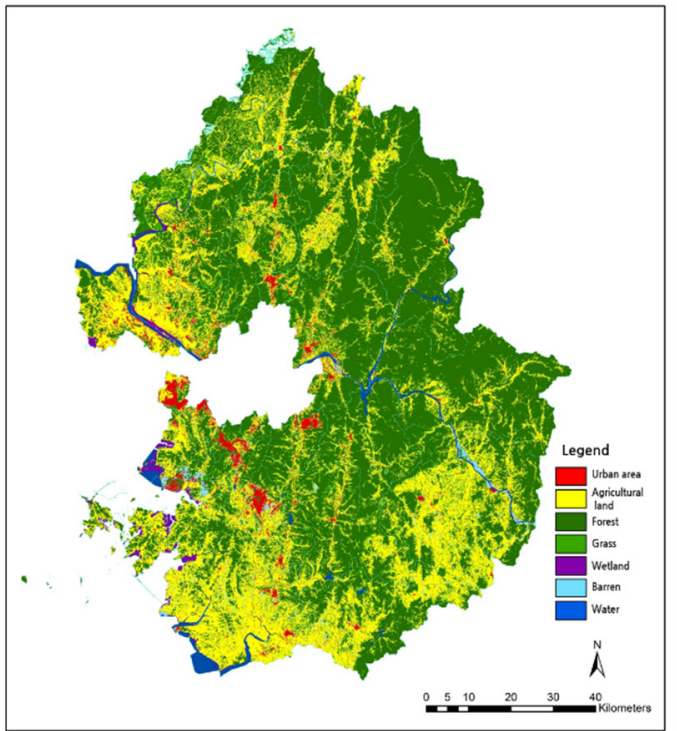

(a)

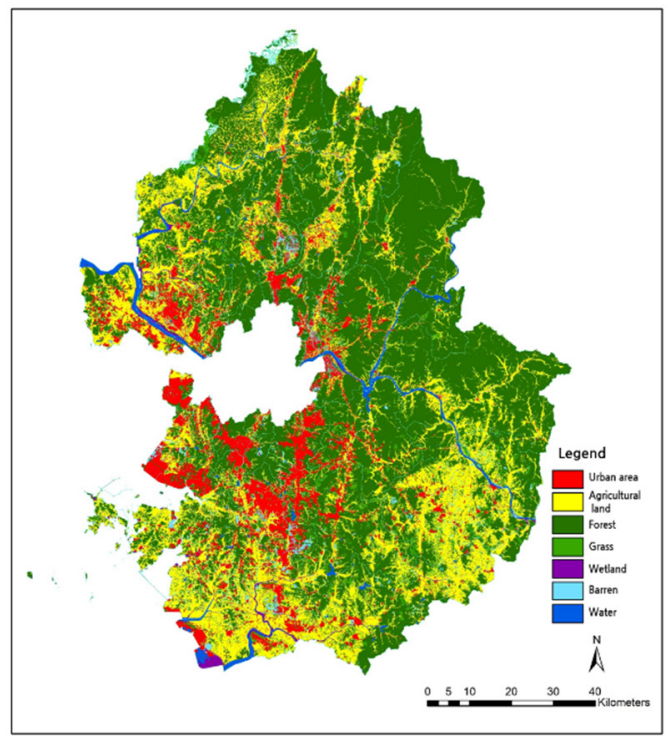

(b)

Figure 3. (a) Landcover map (1988) and (b) land cover map (2018). 


\subsection{MSPA Pattern Changes in Green Area of Each City}

For MSPA of the structural changes in the green areas of each city, GUIDOS [37] was utilized for forest and grass areas among seven land cover types. The analysis was conducted after converting forest types extracted from land cover maps of 1988 and 2018 into Geo Tiff files and then applying a pixel size of $20 \mathrm{~m}$ [38].

GUIDOS (Graphic User Interface for the Description of Image Objects and their Shapes) is a program designed to overcome the limitations of numerical data presented by FRAGSTATS [39], and is an existing landscape pattern analysis program that can intuitively grasp changes in spatial forms. GUIDOS has been widely utilized in diverse fields recently [40-42].

In this study, MSPA (Morphological Spatial Pattern Analysis) analysis was used among various analysis methods of GUIDOS. MSPA has a high potential for being utilized during the establishment of various plans as it presents relations between diverse elements displayed on maps and their distribution patterns in the form of a diagram. In more detail, MSPA showed green areas on a drawing after dividing them into seven types (Core, Islet, Bridge, Loop, Branch, Perforation and Edge) depending on their forms. At the same time, the number of MSPA types of each city was calculated using the following formula (Figure 4). Accordingly, it is very useful for grasping changes in the form of green areas resulting from urbanization, as well as the extinction of dotted green spaces and strip green spaces on a small scale.

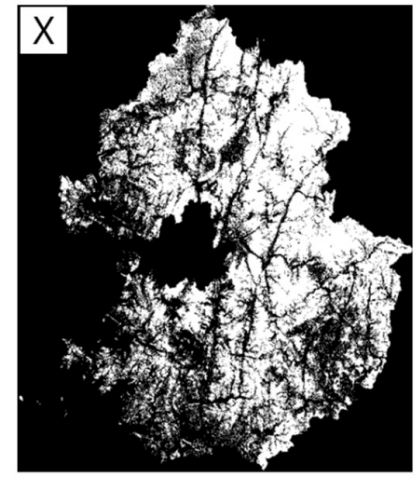

(a)

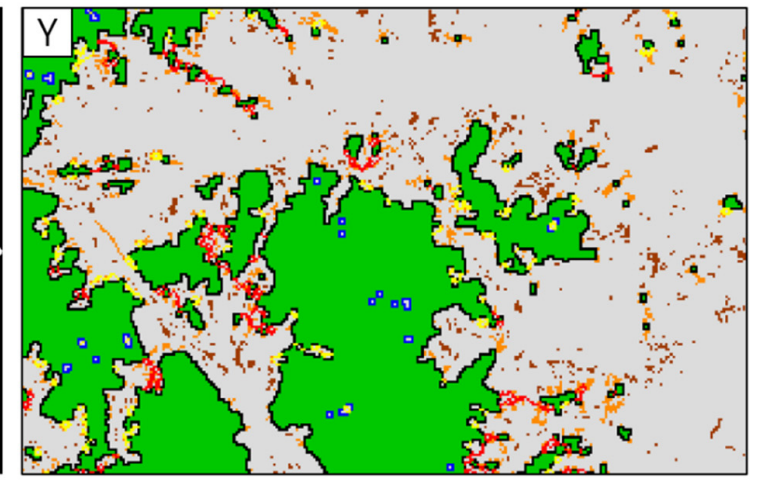

(b)

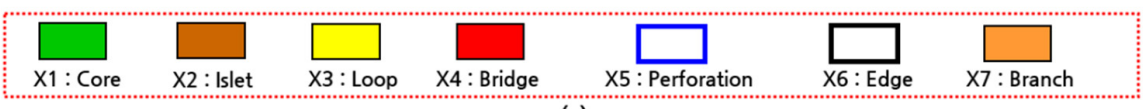

(c)

• $X$ -

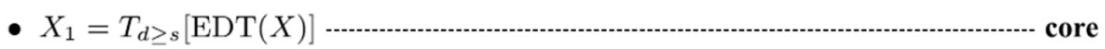

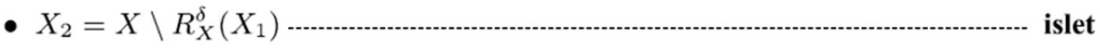

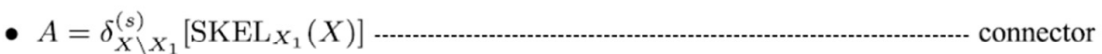

- $X_{3}=$ pixels of $A$ emanating from the same $\mathrm{CC}$ of $X_{1}$................................. loop

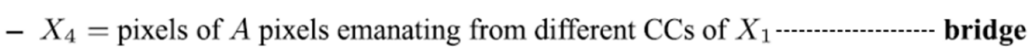

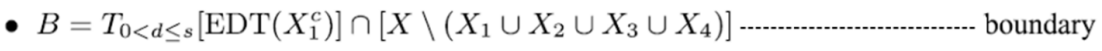

- $X_{5}=$ pixels of $B$ within a distance $s$ to a hole of $B$...-...-...-..-...-...-. perforation

- $X_{6}=B \backslash X_{5}$

- $X_{7}=X \backslash\left\{X_{1} \cup X_{2} \cup X_{3} \cup X_{4} \cup X_{5} \cup X_{6}\right\}$ -

- $Y=\left\{X_{1}, X_{2}, X_{3}, X_{4}, X_{5}, X_{6}, X_{7}\right\}$-.--intern

(d)

Figure 4. (a) Input binary image of research cities, (b) segmented binary pattern, (c) seven categories of MSPA and (d) equation for each step [40]. 
Characteristics of these seven MSPA types are shown as follows (Table 1). First, a Core is a park located in a large-scale forest or a city center. It is a type where the scale is big in comparison with other types. In other words, it is a type that functions as a key space for the inhabitation of biospecies. Next, a Bridge is a strip type that connects different Cores with each other and carries out a function similar to an eco-corridor. An Islet is a green space smaller than a Core. Although it plays an important role as a middle stopover during the movement of wild animals, it is also a type with a very high risk of extinction [43].

Table 1. Morphological spatial pattern analysis (MSPA) categories and ecological implication.

\begin{tabular}{|c|c|}
\hline Categories & Description \\
\hline Core & $\begin{array}{l}\text { It can be used as the "source" of a variety of ecological processes, most of } \\
\text { which are forest parks with large patch areas and large forest farms, etc., which } \\
\text { are of great significance for species reproduction and biodiversity protection }\end{array}$ \\
\hline Islet & $\begin{array}{l}\text { Small patches, which are independent of each other and have low connectivity, } \\
\text { are less likely to communicate with other patches in terms of materials and } \\
\text { energy, and are mostly small green spaces in urban or rural areas. In addition, } \\
\text { an islet is effective in enhancing connectivity by functioning as a stepping } \\
\text { stone green area }\end{array}$ \\
\hline Bridge & $\begin{array}{l}\text { The narrow and long areas connecting the patches of different core areas; they } \\
\text { have the characteristics of ecological corridors, which are mostly green belts, } \\
\text { which are conducive to the migration of species and the connection of } \\
\text { landscape within the territory }\end{array}$ \\
\hline Loop & $\begin{array}{l}\text { The internal channel of material and energy exchange in the same core area; } \\
\text { they are shortcuts for material and energy exchange in the core area }\end{array}$ \\
\hline Branch & $\begin{array}{l}\text { Only one end is connected to the main patch; mainly an extension of the green } \\
\text { space, which is the channel for species diffusion and energy exchange with the } \\
\text { peripheral landscape }\end{array}$ \\
\hline Perforation & $\begin{array}{c}\text { As a transition region, the edge, etc., also exists between the core patch and its } \\
\text { inner non-green space }\end{array}$ \\
\hline Edge & $\begin{array}{l}\text { The transition zone between the marginal zone of the core area and the } \\
\text { peripheral non-green landscape area, which can reduce the impact brought by } \\
\text { the external environment and human disturbance; usually the peripheral } \\
\text { forest zone of forest parks and large forest farms }\end{array}$ \\
\hline
\end{tabular}

\subsection{Cluster Analysis of 31 Cities}

To effectively conduct categorizations by city through a cluster analysis, a factor analysis was conducted first. To enhance the accuracy of the analysis, 12 variables, excluding Grass and Waters, with low communality among a total of 14 selected variables (7 land cover types and 7 MSPA categories), were utilized for the analysis. Factors of these 12 selected variables were extracted through PCA (Principal Component Analysis) [44]. The Varimax Method of Orthogonal Rotation, widely utilized to simplify the characteristics of each factor, was utilized as a Factor Rotation Method. As the analysis was conducted without setting the number of clusters in advance during a cluster analysis based on factor scores, a hierarchical cluster analysis was performed. Hierarchical cluster analysis is a method where two objects close to each other start to form a cluster, and a dendrogram in the shape of a tree is formed through continuous clustering of the clusters adjacent to each other to determine the number of clusters. Ward's Method of hierarchical cluster analysis was used for grouping these 31 cities.

\section{Results}

\subsection{Analysis of Landcover Changes by Each City}

Changes in land coverage areas for each of the 31 cities are as follows (Table 2). First, in the case of Hwaseong, the increase in urbanized areas was found to be the biggest among the 31 cities. On the contrary, its sizes of agricultural areas, forest, wetland, and waters decreased. In particular, the sizes of its agricultural areas and wetland decreased by 7600 ha and 1705 ha, respectively. Decreases in the areas of these two land cover types were found 
to be the biggest among the 31 cities. Next, forest areas decreased by 2600 ha. The decrease in the area of natural space due to urbanization was noticeable in Hwaseong as a whole. In the case of Pyeongtaek, its urbanized areas increased by 6296 ha. It was found to be a city showing the second biggest increase in urbanized areas, following Hwaseong. Its farmland areas decreased by 7233 ha. It was found to be a city showing the second biggest decrease in farmland areas, following Hwaseong. Its forest areas decreased by 1325 ha. On the contrary, its grassland and wetland areas increased by 618 ha and 1737 ha, respectively.

In the case of Namyangju, its land cover types that showed increases in size were found to be urbanized areas, bare land, and waters (Figure 5). On the contrary, its land cover types that showed decreases in size were found to be agricultural areas, forest, grassland, and wetland. In particular, forest areas in Namyangju decreased by about 3900 ha due to urbanization. It was found to be a city showing the second biggest decrease in forest area, following Yongin. In the case of Siheung, its land cover types that showed increases in size were found to be urbanized areas and grassland. On the contrary, its land cover types that showed decreases in size were found to be agricultural areas, forest, wetland, and waters. In particular, its areas of wetland and waters decreased by 1286 ha and 1514 ha, respectively, due to large-scale reclamation projects that appeared in the areas close to the coast. Due to such reclamation projects, wetland and waters were converted to farmland and urbanized areas.

On the contrary, in the case of Gwacheon, Dongducheon, and Uiwang, urbanized areas increased by $193 \mathrm{ha}, 503 \mathrm{ha}$ and $601 \mathrm{ha}$, respectively. In particular, forest areas in Gwacheon and Dongducheon increased differently from other cities. This was because farmland and bare land located in the forests were converted into forests. When we put these results together, urbanized areas were found to have increased in all 31 cities. It was found that urbanization was concentrated in cities adjacent to Seoul, the capital. In addition, most of the forest, grassland, and wetland areas with high ecological values were found to show decreases in size due to urbanization.

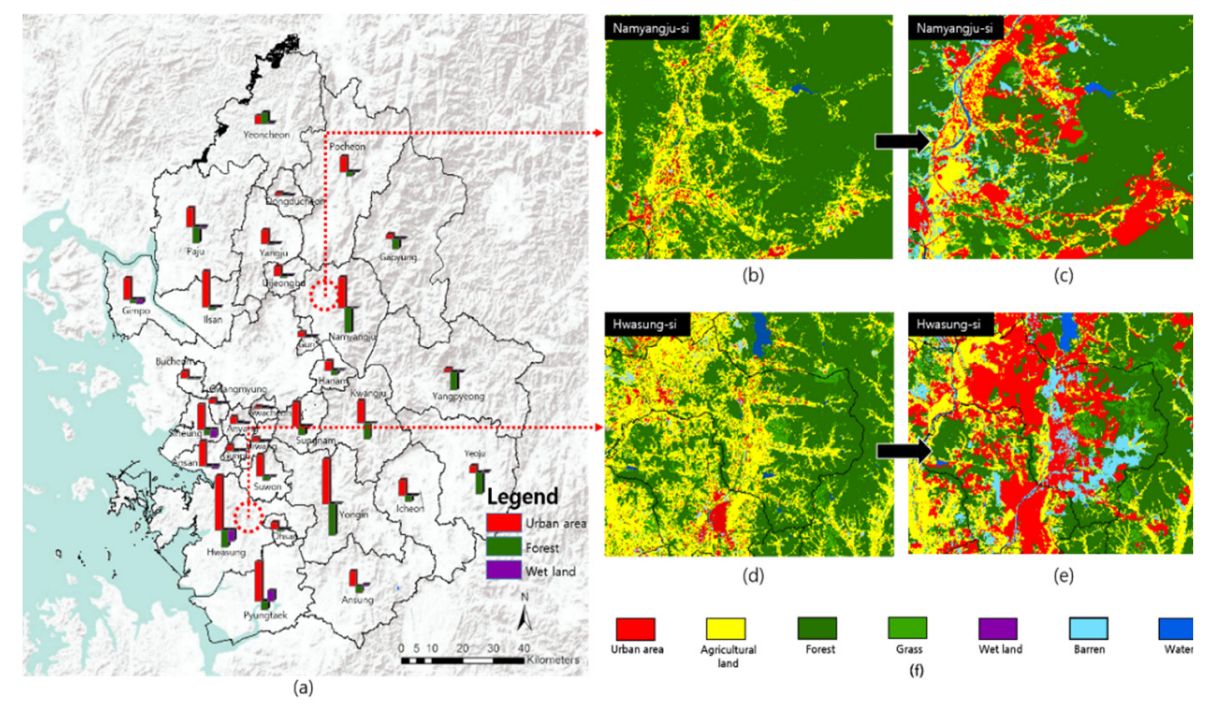

Figure 5. (a) Changes in major land cover by total city, (b) 1988 land cover map of Namyangju, (c) 2018 land cover map of Namyangju, (d) 1988 land cover map of Hwaseong, (e) 2018 land cover map of Hwaseong, and (f) legend of land cover. 
Table 2. Changes in land cover type areas by city (2018-1988) Unit: ha.

\begin{tabular}{|c|c|c|c|c|c|c|c|}
\hline Division & Urban Area & Agricultural Land & Forest & Grass & Wetland & Barren & Water \\
\hline Gapyeong & 695.24 & -950.63 & -1511.13 & 1044.13 & -1.31 & 385.59 & 33799 \\
\hline Goyang & 5688.11 & -5789.74 & -441.85 & -185.05 & -15.24 & 794.60 & 86.48 \\
\hline Gwacheon & 193.32 & -338.93 & 159.62 & -115.88 & 2.01 & 100.42 & -0.33 \\
\hline Gwangmyeong & 668.63 & -611.38 & -209.67 & 111.89 & 24.41 & 17.31 & -0.49 \\
\hline Gwangju & 3565.62 & -727.47 & -2518.27 & -522.29 & -1.53 & 125.61 & 78.32 \\
\hline Guri & 717.07 & -736.47 & -119.85 & -191.99 & -1.68 & 285.31 & 48.34 \\
\hline Gunpo & 839.36 & -417.37 & -138.19 & -317.95 & 4.88 & 19.85 & 9.45 \\
\hline Gimpo & 3346.53 & -4033.38 & -477.35 & 660.85 & -661.73 & 638.35 & 525.64 \\
\hline Namyangju & 4887.68 & -1762.00 & -3893.74 & -603.03 & -6.25 & 1275.71 & 101.63 \\
\hline Dongducheon & 503.07 & -534.42 & 165.59 & -302.75 & 0.00 & 180.23 & -11.73 \\
\hline Bucheon & 1106.49 & -1204.96 & -97.41 & 191.61 & -12.99 & 16.71 & 0.46 \\
\hline Seongnam & 3737.96 & -1967.57 & -1390.05 & -599.82 & 1.67 & 191.00 & 26.90 \\
\hline Suwon & 3465.44 & -2384.74 & -590.55 & -365.06 & -23.54 & -151.07 & 49.52 \\
\hline Siheng & 3920.09 & -1059.52 & -920.43 & 182.25 & -1286.49 & 677.93 & -1514.39 \\
\hline Ansan & 3868.27 & -1045.76 & -193.47 & -292.40 & -395.83 & -1256.51 & -684.71 \\
\hline Anseong & 2328.93 & -3439.41 & -1072.45 & 1207.44 & 248.58 & 416.41 & 310.35 \\
\hline Anyang & 1060.33 & -767.78 & 71.54 & -345.75 & 9.59 & -26.93 & -0.68 \\
\hline Yangju & 2167.23 & -2846.65 & -192.94 & -964.60 & 19.74 & 1785.28 & 31.97 \\
\hline Yangpyeong & 451.60 & 1392.15 & -2949.07 & 722.90 & -3.79 & 339.36 & 47.25 \\
\hline Yeoju & 1054.44 & 374.18 & -3336.62 & 1129.63 & 128.86 & 400.46 & 249.24 \\
\hline Yeoncheon & 1240.57 & -1354.95 & 1755.13 & -2062.68 & 76.26 & 128.85 & 221.89 \\
\hline Osan & 1163.97 & -944.33 & -286.36 & -135.66 & 8.49 & 183.58 & 10.31 \\
\hline Yongin & 7130.08 & -2978.75 & -4976.87 & -115.09 & 40.98 & 748.52 & 151.12 \\
\hline Uiwang & 600.60 & -406.09 & -105.01 & -252.72 & 0.33 & 145.49 & 17.39 \\
\hline Uijeongbu & 1486.09 & -1073.46 & -292.48 & -386.06 & 1.56 & 253.46 & 10.82 \\
\hline Icheon & 2426.24 & -1974.78 & -976.91 & -581.47 & -0.96 & 1092.76 & 16.01 \\
\hline Paju & 2990.49 & 1274.16 & -2585.27 & -3131.46 & -276.22 & 1073.22 & 655.89 \\
\hline Pyeongtaek & 6296.37 & -7232.52 & -1325.11 & 869.68 & 1737.38 & 1375.68 & -1724.09 \\
\hline Pocheon & 2416.37 & -3083.93 & -645.79 & 3.05 & 68.83 & 1088.78 & 153.31 \\
\hline Hanam & 1402.77 & -1506.13 & -734.63 & 364.14 & 38.92 & 219.31 & 216.10 \\
\hline Hwaseong & 8598.49 & -7597.43 & -2637.48 & 617.70 & -1705.32 & 3221.19 & -498.11 \\
\hline
\end{tabular}

\subsection{MSPA Pattern Changes in Green Area of Each City}

Regarding MSPA changes for each of the cities, the results are as follows (Table 3). First, in the case of Yeoju, a city with the biggest number of Cores and Branches, it showed decreases compared to the data of the late 1988. In addition, the number of Bridges and Loops greatly decreased because most of its linear green areas with relatively small sizes ceased to exist due to the expansion of urbanized areas and increases in farmland areas. Moreover, Islets with small size green areas that could have played an important role as stepping-stone green areas greatly decreased in number.

In the case of Goyang, the number of Islets among the seven MSPA types decreased by 1322 when compared to that of 1988. Such a result was due to an increase in urbanized areas resulting from its geographical characteristic of being close to Seoul, as shown earlier in the land coverage changes. In addition, Cores known to play an important role as habitat spaces for biospecies also greatly decreased in number. In the case of Hwaseong (Figure 6), the number of Islets decreased by 3963, the biggest decrease among the 31 cities due to the urbanization of the last 30 years. Its Branches and Bridges also greatly decreased in number. Nevertheless, it is worth noting that its Cores increased in number because large scale green lands were fragmentized due to new constructions of roads and developments. Anseong was found to show changes in the spatial structure of green lands different from other cities. The result of MSPA showed that Cores, Loops, Bridges, and Branches increased in number in Anseong due to an increase in grassland areas among the land cover types. Next, in the case of Guri, Perforations belonging to the type arising from land use by humans in forests showed the biggest increase in number among the 31 cities. On the contrary, Perforations in Yangpyeong and Yongin decreased greatly in number due to the prohibition of farming 
activities, which took place in forests and forestation projects. MSPA drawings for 1988 and 2018 for all 31 cities are presented as Appendix A.

Table 3. Changes in MSPA categories by city (2018-1988).

\begin{tabular}{|c|c|c|c|c|c|c|c|}
\hline Division & Core & Islet & Perforation & Edge & Loop & Bridge & Branch \\
\hline Gapyeong & -183 & 105 & -261 & -342 & 109 & -189 & -944 \\
\hline Goyang & -127 & -3122 & -51 & -536 & -122 & -167 & -720 \\
\hline Gwacheon & 3 & -30 & 5 & -20 & 5 & -18 & -34 \\
\hline Gwangmyeong & 1 & -258 & -1 & -49 & -24 & -7 & -65 \\
\hline Gwangju & -138 & 128 & -425 & -878 & -175 & -235 & -814 \\
\hline Guri & -42 & -79 & 166 & -109 & -16 & -25 & -129 \\
\hline Gunpo & -6 & -129 & -12 & -114 & -17 & -35 & -83 \\
\hline Gimpo & -61 & -1284 & 8 & -155 & -49 & -30 & -396 \\
\hline Namyangju & -284 & 793 & -443 & -1148 & -123 & -397 & -900 \\
\hline Dongducheon & -70 & -109 & 28 & -172 & -24 & -72 & -272 \\
\hline Bucheon & 4 & -263 & 2 & 28 & -6 & 4 & -30 \\
\hline Seongnam & -46 & -151 & -158 & -432 & -196 & -57 & -393 \\
\hline Suwon & -46 & -979 & -10 & -223 & -71 & -62 & -308 \\
\hline Siheng & -16 & -336 & -58 & -332 & -90 & -79 & -313 \\
\hline Ansan & 0 & -935 & -15 & -270 & -90 & -40 & -356 \\
\hline Anseong & 172 & -990 & -126 & 372 & 175 & 41 & 819 \\
\hline Anyang & -21 & -216 & -57 & -120 & -80 & -31 & -190 \\
\hline Yangju & -240 & -547 & -144 & -1040 & -107 & -296 & -979 \\
\hline Yangpyeong & -370 & -236 & -892 & -1695 & -113 & -460 & -1423 \\
\hline Yeoju & -514 & -1575 & -55 & -2008 & -350 & -462 & -2387 \\
\hline Yeoncheon & -313 & -1004 & 38 & -1093 & 2 & -411 & -1302 \\
\hline Osan & -63 & -308 & -6 & -171 & -38 & -50 & -348 \\
\hline Yongin & -43 & -63 & -475 & -680 & -231 & -205 & -539 \\
\hline Uiwang & -7 & -51 & -83 & -136 & -73 & -24 & -31 \\
\hline Uijeongbu & -11 & -215 & -30 & -168 & -64 & -20 & -144 \\
\hline Icheon & -45 & -2143 & -7 & -74 & 38 & -81 & -375 \\
\hline Paju & -284 & -1944 & -337 & -2040 & -337 & -484 & -1712 \\
\hline Pyeongtaek & -124 & -2190 & -16 & -275 & 7 & -134 & -493 \\
\hline Pocheon & -357 & -2329 & -55 & -1302 & -72 & -301 & -1705 \\
\hline Hanam & -18 & -88 & -41 & -96 & -26 & -24 & -188 \\
\hline Hwaseong & 60 & -3963 & -39 & -869 & -419 & -116 & -824 \\
\hline
\end{tabular}




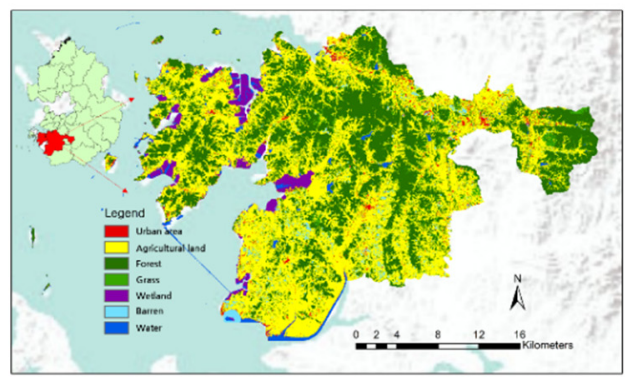

(a)

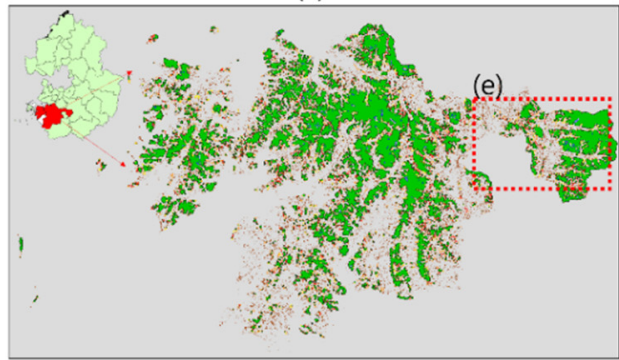

(c)

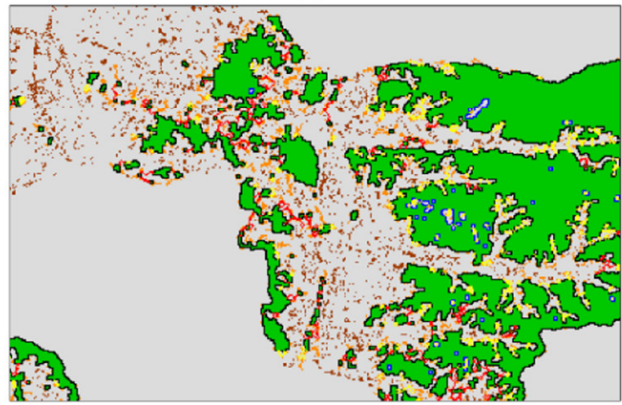

(e)

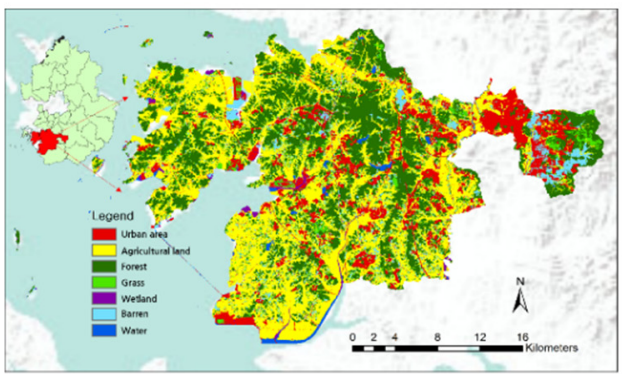

(b)

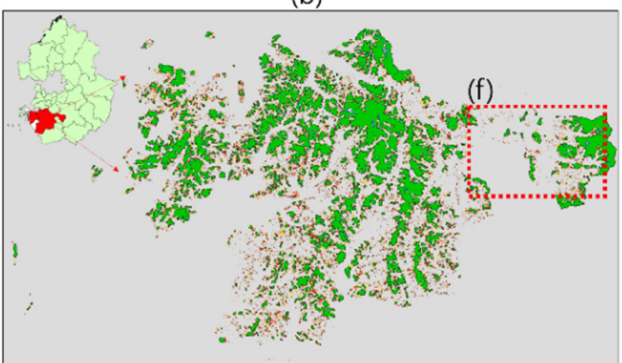

(d)

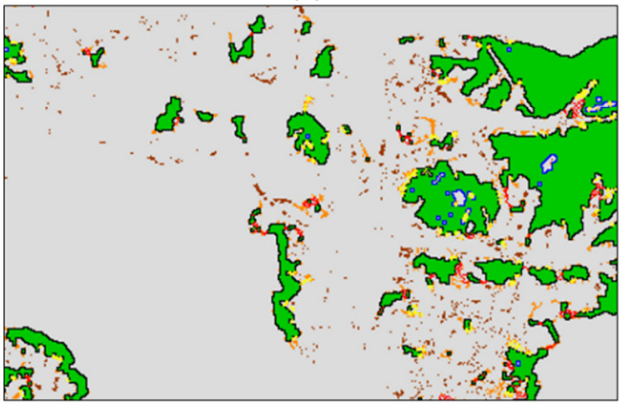

(f)

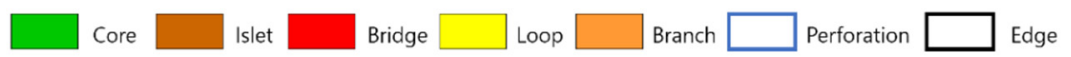

(g)

Figure 6. (a) 1988 land cover map of Hwaseong, (b) 2018 land cover map of Hwaseong, (c) 1988 MSPA map of Hwaseong (d) 2018 MSPA map of Hwaseong, (e) detailed view of map (c), (f) detailed view of map (d), and (g) legend of MSPA categories.

\subsection{Cluster Analysis of 31 Cities}

As a result of factor analysis, which utilized a total of 12 variables selected for categorization by city, factors were classified into a total of four (Table 4). These four factors converged a total of 25 times according to the Varimax Method. They explained about $88 \%$ of the total variance. The communality of the 12 variables was found to have high values (not smaller than 0.7). In addition, the KMO (Kaiser-Meyer-Olkin) value, which was the result of conducting a goodness of fit test of the measuring tool, was 0.575 , meaning that there was no problem in selecting these variables. The goodness of fit of this model was found to be very high, because the probability value was found to be 0.00 in Bartlett's test of sphericity. Thus, there were significant differences, and commonality existed for the 12 selected variables.

The characteristics of each classified factor are shown as follows. First, the four variables belonging to Factor-1 were "Branch", "Core", "Bridge" and "Edge". They had an explanatory power of about $34 \%$ for the total variance. They were found to be variables with a high importance in the aspect of green networks. The reason these four variables are grouped un the same factor is because the annihilation of the Core directly affects the Branch, Bridge, and Edge. In fact, in the case of Yeoju, the number of Cores decreased the 
most, and at the same time, the number of Branches and Bridges existing in a linear form at the edge of the forest also decreased significantly compared to other cities.

Next, Factor-2 had an explanatory power of about 24\%. It included "Agricultural Land", "Urban Area", "Barren", and "Islet". "Urban Area" and "Barren" showed negative values, differently from other variables. This was because "Urban Area" and "Barren" increased in size, contrary to the other 12 variables, for which the size or the number decreased when compared to those of 1988. Like this, the variables of Factor-2 were found to play an important role in clustering cities, with changes in the size of farmland due to the expansion of urbanized areas. Changes in Islets known to function as stepping-stone green areas were similar (i.e., highly urbanized cities). Factor-3 was made up of "Perforation" and "Forest". Its explanatory power was found to be about $17 \%$. The reason these two variables are grouped as the same factor is because the disappearance of Perforation is directly related to the forest. As defined in Table 2, Perforation is a non-green space that appears in the forest, and is a variable that disappears when the forest is destroyed. In fact, looking at the cases of Yongin and Namyangju, it was found that the number of Perforations greatly decreased as the areas of forest decreased. Lastly, Factor- 4 had an explanatory power of about $12 \%$. This factor had a high effect on the grouping of cities in which time-sequential changes of "Wetland" and "Loop" were similar.

Table 4. Results of factor analysis.

\begin{tabular}{ccccc}
\hline Factor & Factor-1 & Factor-2 & Factor-3 & Factor-4 \\
\hline Branch & 0.965 & 0.112 & 0.100 & 0.113 \\
Core & 0.961 & -0.080 & 0.101 & -0.145 \\
Edge & 0.927 & 0.083 & 0.288 & 0.185 \\
Bridge & 0.920 & 0.036 & 0.316 & -0.021 \\
Agricultural land & -0.236 & 0.926 & -0.061 & -0.142 \\
Urban area & 0.083 & -0.826 & -0.400 & -0.168 \\
Barren & -0.234 & -0.781 & -0.135 & -0.173 \\
Islet & 0.283 & 0.778 & -0.318 & 0.195 \\
Perforation & 0.330 & -0.146 & 0.856 & -0.029 \\
Forest & 0.276 & 0.251 & 0.853 & 0.136 \\
Wetland & -0.087 & 0.069 & -0.018 & 0.942 \\
Loop & 0.471 & 0.317 & 0.323 & 0.609 \\
Eigen value & 4.173 & 2.971 & 2.050 & 1.463 \\
Explained amount of & 34.777 & 24.759 & 17.084 & 12.190 \\
total variance (\%) & & & 76.620 & 88.810 \\
Cumulative & 34.777 & 59.536 & &
\end{tabular}

Based on these results of the factor analysis, 31 cities in Gyeonggi-do were classified into six clusters (Figure 7). Cluster-1 was made up of 15 cities, the biggest number of cities, which included Gwangmyeong, Gunpo and Anyang. Cluster-2 was a cluster made up of five cities, including Suwon, Gimpo and Goyang. Cluster-3 was made up of Gwangju, Namyangju, Yangpyeong and Yongin. Cluster-4 had five cities, Yeoju, Paju, Yangju, Pocheon and Yeoncheon, that showed similar environmental changes. Cluster-5 was an independent cluster formed by Pyeongtaek alone. Cluster-6, too, was an independent cluster formed by Hwaseong alone. 


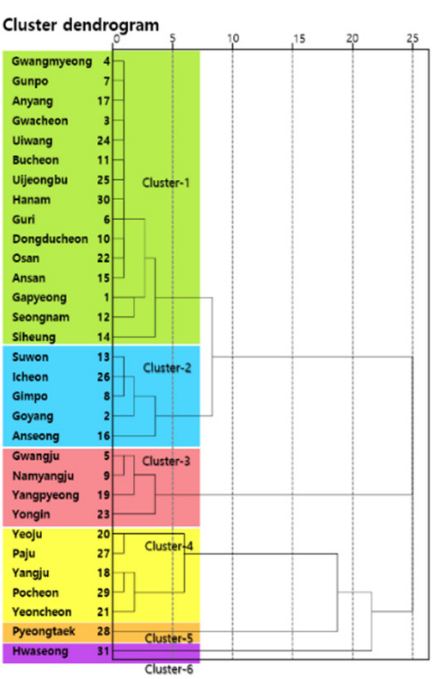

(a)

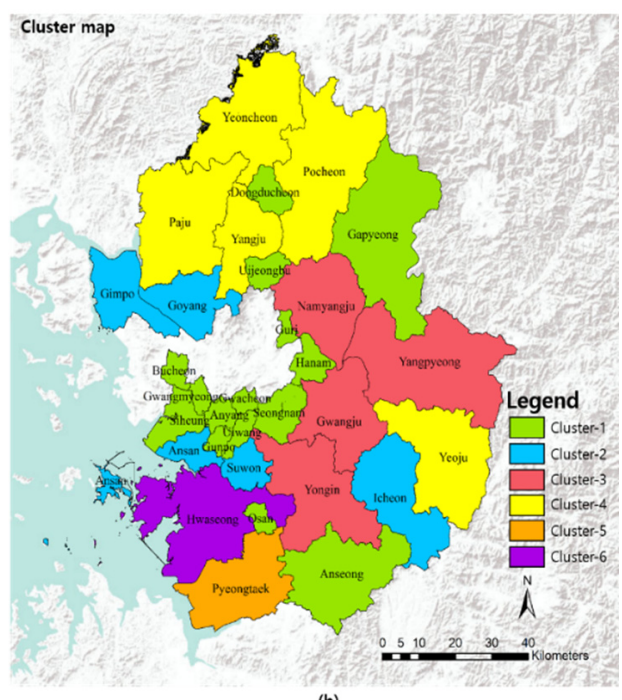

Figure 7. (a) Cluster dendrogram and (b) cluster map of research cities.

\section{Discussion}

\subsection{Discussion and Limitation}

In the present study, we determined changes in land coverage and changes in MSPA values in each of the 31 satellite cities surrounding Seoul for about 30 years, from 1988 to 2018. Cities that showed similar environmental changes were grouped. First, for changes in land coverage, urbanized areas in all 31 cities were found to have increased. In particular, urbanization was concentrated in cities adjacent to Seoul, the capital. For example, in the case of Goyang (Figure 8), most spaces that were farmland in the past were converted into urban areas due to such geographic characteristics. As a result, forest, grassland and wetland with high ecological values greatly decreased in size. Accordingly, for large cities such as Suwon, Icheon, Gimpo and Siheung, which showed environmental changes similar to those of Goyang, it is particularly important to preferentially search for a plan to effectively preserve natural spaces with high values in advance when establishing development plans.

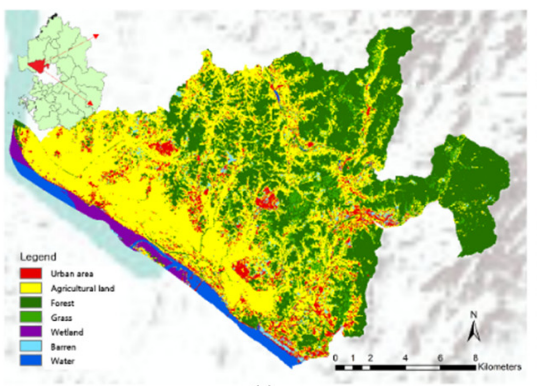

(a)

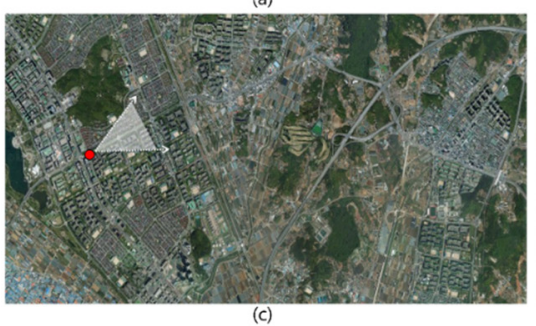

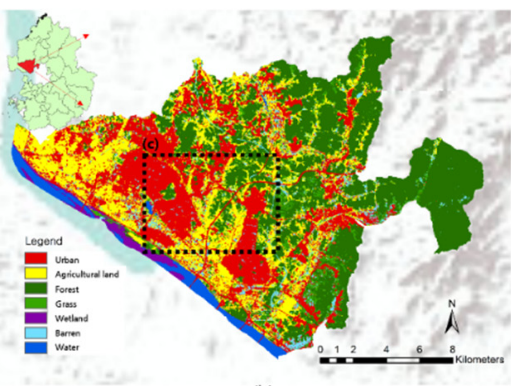

(b)

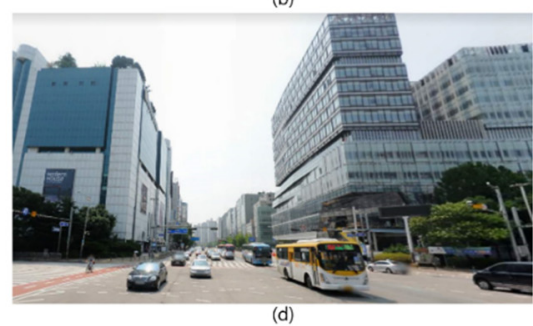

Figure 8. (a) 1988 land cover map of Goyang, (b) 2018 land cover map of Goyang, (c) satellite image of map (b,d) road view of map (c) Most of the space that used to be agricultural land has been converted into urbanization areas. 
Next, when we look into the results after analyzing changes in MSPA category in each of the 31 cities, 103 Cores and 733 Islets were found to have decreased, on average, in these 31 cities. A total of 115 Perforations, 521 Edges, 83 Loops, 144 Bridges and 567 Branches decreased on average. As can be seen from such an analysis result, Cores that are key green lands and Islets that are stepping-stone green lands have ceased to exist in most cities due to the urbanization that has progressed for several decades, meaning that the green network function is greatly deteriorated at a whole city level. Accordingly, an environmental plan should be established with a focus on quantitatively/qualitatively securing green lands by creating additional green lands of diverse sizes and forms to recover the function of green networks.

To look into the characteristics of each of these six clusters in more detail, the average value of the factor of each cluster was calculated based on the characteristics examined (Table 5). In particular, as factors with a positive value and a negative value appeared in a mixture in Factor-2, among the four factors, the Agricultural Lands and Islets with decreased sizes and numbers were classified as Detailed Factor 2-1, and Urban Areas and Barrens with increased sizes were classified as Detailed Factor 2-2.

Table 5. Factor score average by cluster (the numbers in bold indicate the average value of the highest or lowest factor among the six clusters and can represent the characteristics of each cluster).

\begin{tabular}{|c|c|c|c|c|c|c|}
\hline \multirow{2}{*}{ Factor } & \multirow{2}{*}{ Cities } & \multirow{2}{*}{ Factor-1 } & \multicolumn{2}{|c|}{ Factor-2 } & \multirow{2}{*}{ Factor-3 } & \multirow{2}{*}{ Factor-4 } \\
\hline & & & $2-1$ & $2-2$ & & \\
\hline Cluster-1 & $\begin{array}{l}\text { Gwangmyeong, Gunpo, Anyang, } \\
\text { Gwacheon, Uiwang, Bucheon, } \\
\text { Uijeongbu, Hanam, Guri, } \\
\text { Dongducheon, Osan, Ansan, } \\
\text { Gapyeong, Seongnam, Siheung }\end{array}$ & 0.62999 & 0.44254 & -0.48388 & 0.39217 & 0.23549 \\
\hline Cluster-2 & $\begin{array}{c}\text { Suwon, Icheon, Gimpo, Goyang, } \\
\text { Anseong }\end{array}$ & 0.35109 & -0.60356 & 0.08633 & 0.42075 & -0.05106 \\
\hline Cluster-3 & $\begin{array}{l}\text { Gwangju, Namyangju, } \\
\text { Yangpyeong, Yongin }\end{array}$ & -0.83973 & 0.63843 & 0.40742 & -1.96838 & -0.24216 \\
\hline Cluster-4 & $\begin{array}{c}\text { Yeoju, Paju, Yangju, Pocheon, } \\
\text { Yeoncheon }\end{array}$ & -1.60644 & -0.22083 & 0.11427 & 0.02580 & -0.29516 \\
\hline Cluster-5 & Pyeongtaek & 0.11024 & -2.03963 & 1.43641 & 0.13906 & 2.08189 \\
\hline Cluster-6 & Hwaseong & 0.07547 & -3.03028 & 3.18919 & -0.38086 & -2.91448 \\
\hline
\end{tabular}

First, Cluster- 1 was found to be the cluster for which the score for Factor- 1 was higher than that of any other cluster. That is, it is a cluster without a big environmental change. In reality, Cores, Branches, and Bridges were found to have decreased less in relevant cities than in cities of other clusters, although urbanization progressed. It was worth noting that the extinction of green lands was not high in Bucheon, Hanam, Guri, or Gwacheon, although these cities were very close to Seoul, the capital. Such a result is attributable to the restriction on development enforced by designating forests of relevant cities as Greenbelts to prevent the thoughtless expansion of Seoul. However, as Greenbelts are released gradually due to continuous development pressure, the emphasis should be put on maintaining the function of green networks by minimizing the extinction of small-scale green lands of diverse forms such as Branches, Bridges, Islets, etc., when development plans are established.

Cluster-2 was a cluster made up of five cities, including Suwon, Gimpo and Goyang, that were classified as relatively large cities. It showed the highest value for Factor-3 among the four Factors, meaning that its decrease in forest area was not high compared to the other clusters. However, it showed negative values for Factor-4 and Factor-2-1. Its spaces with high values such as wetland, stepping-stone green lands, etc., greatly decreased in number due to urbanization. In addition, as cities belonging to this cluster are still under high development pressure due to the continuous population increase and industrial development, emphasis should be put on the arrangement of a plan to preserve natural resources with high ecological values. 
Cluster-3 was made up of Gwangju, Namyangju, Yangpyeong and Yongin. It was a cluster that showed a negative score for Factor-3. This cluster had a higher score for Factor -3 than the other clusters. Thus, it was a cluster with a large decrease in forest area. Further, as it had a big negative value for Factor-1, it was characterized by a big decrease in the number of linear connection green lands such as Branches, Bridges, etc. Accordingly, cities in the relevant cluster should put an emphasis on the minimization of additional damage to and the fragmentation of forests, while preserving small linear green lands at the same time.

Cluster-4 was a cluster made up of Yeoju, Paju, Yangju, Pocheon and Yeoncheon. It showed a higher negative value for Factor-1 than the other clusters. It was characterized by a big decrease in the actual number of large-scale green lands and linear green lands of diverse forms. As such a decrease in the number of green lands will lead to a decrease in the function of urban green networks, it is desirable to prioritize the creation of additional green lands to enhance green land connectivity when environmental plans are established.

Cluster-5 was an independent cluster formed by Pyeongtaek alone. It showed the highest positive value for Factor-4 among the four Factors. In fact, Pyeongtaek was the city with the largest increase in wetland areas. Accordingly, environmental plans should be established with an emphasis on the effective preservation of wetland and swamps that play an important role as habitats for biospecies.

Lastly, Cluster- 6 was an independent cluster formed by Hwaseong alone, a city with the highest negative value for Factor- 4 . That is, this city had the biggest decrease in wetland areas. In addition, Cluster- 6 showed larger changes for Factor 2-1 and 2-2 than the other clusters. As a whole, Cluster- 6 showed a large environmental change due to urbanization. Accordingly, quantitative expansion of green spaces through the creation of additional green lands, and the establishment of a systematic preservation and management plan for wetland and swamps, should be preferentially considered for Hwaseong in order for it to function as an environmentally sustainable city.

From a small specific unit space to a large-scale city and even regional and territorial space, it is predicted that future land space will be more directly affected by numerous developments. Therefore, how will the various impacts caused by development change the future land space? By what means and methods will we be able to control the influencing factors and change processes in a natural environment and landscape-friendly way? In this respect, the results of this study are different from other related studies in that they involve clustered cities at the regional level and are based on the results of time-series environmental changes. The results thus present directions for establishing environmental policies for each cluster.

First, among studies examining environmental changes using landcover change [45-48], Kumar et al. [49] used land cover types in 1976, 1989, 2000 and 2014 for Usri watershed. They looked at the changes in the landscape matrix, and based on these analysis results, clustered land cover types showing similar values for each year. However, a limitations is that the scope of the space was limited to a specific watershed and that the analysis result could not be visually confirmed.

In addition, in the case of Korea, the consideration of the physical environment and the human psychological behavior aspect rather than the natural environment factor is considered more important in figuring out the value of the city. Lee's [50] research emphasizes the need for qualitative growth such as the quality of life rather than quantitative growth focusing on economic aspects. For this purpose, the 31 cities in Gyeonggi-do were grouped based on the Physical Environment Satisfaction and Neighborhood Satisfaction indices. Of the total of 14 indicators used for grouping, it was found that one of the indicators related to the natural environment was satisfaction with the park.

As evidenced by numerous studies, urban land use and environmental changes are inevitable phenomena in the process of urban development. Therefore, the Fragstats program, using the land cover map, has been used importantly in diagnosing environmental changes due to urbanization, but the fact that the analysis results cannot be looked at in drawings is a big limitation. In this aspect, the MSPA analysis used in this study is different 
in that the analysis results are presented in drawings. In addition, the results of this study are environmentally friendly in that they suggest a direction for establishing differentiated environmental policies for each city, such as the quantitative expansion of green areas, conservation of small-scale linear green areas, wetland conservation, and minimization of forest fragmentation in connection with land cover change. However, since a city is a space where humans and nature coexist, it is judged that it is desirable to comprehensively consider factors such as the physical environment and human psychological behavior, not just the natural environment aspect.

However, in order to increase the effectiveness of the study, it is necessary to additionally consider the following aspects in future studies. First, environmental changes in cities need to be determined using more detailed basic data. In Korea, a City Biotope Map was recently prepared with a high spatial resolution of a $5 \mathrm{~m}$ level on a national scale pursuant to Article 34-2 (Preparation/Utilization of City Biotope Map) of the Natural Environment Conservation Act. Accordingly, it is required to determine environmental changes by actively utilizing a more detailed basic map such as a City Biotope Map and to establish environmental plans based on it. Moreover, the present study had another limitation: the cities were clustered based on results of changes in land coverage and spatial structures of green lands. Accordingly, it is desirable to determine environmental changes in cities comprehensively by taking into account the values of diverse aspects such as soil, air, surface temperature and water quality and supply, as well as endangered species, etc., to find the appropriate direction to take when coping with such environmental changes based on the results of such determinations.

\subsection{Policy Proposal}

Although spatial plans for national land are established in Korea for each of the diverse spatial scales, such as Comprehensive National Territorial Plans, Metropolitan City Plans, Si/Gun Master Plans, etc., when we take into account the fact that concrete and detailed physical plans established under the premise of implementation are realized at a city level, we can see that establishing differentiated environmental plans for sustainable land use management based on time-sequential environmental changes at a city space level is very important.

However, most environmental policies established for many cities that belong to the same area (Gyeonggi-do, Gyeongsangbuk-do, etc.) put emphasis on the quantitative expansion of green lands. Accordingly, it is important to grasp time-sequential environmental changes and secure environmental drawings that can be connected to development plan drawings at the same time to establish differentiated environmental policies. In Korea, although a Biotope Map is built and renewed at five-year intervals based on Article 34-2 (Preparation/Utilization of Biotope Map) of the Natural Environment Conservation Act, there is no mandatory provision that forces its utilization when establishing development plans. Accordingly, the law/system is required to be reinforced to obtain basic data so that a Biotope Map or Ecosystem Service Map is mandatorily taken into account when establishing development plans.

Moreover, when we look into the budget of each ministry of the Korean government as of 2020, the budget of the Ministry of Environment was much smaller than that of the other ministries. It was about KRW 9 trillion, while that of the Ministry of Land, Infrastructure, and Transport was about KRW 50 trillion, that of the Ministry of National Defense was about KRW 50 trillion, and that of the Ministry of Employment and Labor was about KRW 30 trillion. Accordingly, to build diverse basic data and diagnose environmental changes in cities, the expansion of the budget is required. Each city is also required to use more of their budget for the preservation and management of the environment.

In addition, for sustainable urban development, the connection between disciplines that are being pursued in different perspectives, laws, and administrative organizations will be of utmost importance. For example, the natural environment conservation plan is mainly researched in the field of biology, the park and green space plan in the landscape field, and 
the artificial landscape plan in the field of architecture and civil engineering. However, as mentioned earlier, transdisciplinary cooperation to diagnose and solve environmental problems by integrating and synthesizing problems themselves for environmentally sustainable city development is more important than dealing with each environmental problem as a separate entity [51,52].

\section{Conclusions}

As pressure on the suburbs of large cities is increasing worldwide, this study examined land cover changes and MSPA changes over the past 30 years in 31 cities adjacent to the capital of Korea, Seoul. Cities with similar patterns were clustered based on the analysis results. Based on these results, this study is meaningful in that it suggests the characteristics of environmental change for each community and the direction of environmental planning based on these.

However, in the case of Korea, a number of development plans are scheduled for small and medium-sized cities that have not experienced significant environmental change compared to large cities. Therefore, prior to development plans, it is necessary to identify high-value environmental resources, key green areas for green network construction, and major habitats for species conservation, and to establish an urban development plan that prioritizes these spaces.

In addition, we believe that transdisciplinary cooperation is more important than ever. Therefore, experts in land use planning, landscape planning, forest planning, traffic planning, and climate change planning, which are all highly related to urban development planning, need to actively reflect their research results in urban development plans. It is judged that only if these efforts are supported, it will be possible to develop the national space more environmentally and sustainably.

Author Contributions: Conceptualization, J.-H.K. and O.-S.K.; methodology, J.-H.K.; validation, J.-H.K. and O.-S.K.; formal analysis, J.-H.R.; investigation, J.-H.K. and O.-S.K.; resources, J.-H.K.; data curation, O.-S.K. and J.-H.K.; writing, J.-H.K., J.-H.R.; supervision, J.-H.R. All authors have read and agreed to the published version of the manuscript.

Funding: This research received no external funding.

Institutional Review Board Statement: Not applicable.

Informed Consent Statement: Not applicable.

Data Availability Statement: Not applicable.

Conflicts of Interest: The authors declare no conflict of interest.

\section{Appendix A}

Table A1. Current status of 31 cities.

\begin{tabular}{|c|c|c|c|}
\hline City Name & $\operatorname{Area}\left(\mathrm{km}^{2}\right)$ & Population & Location and Characteristics \\
\hline Gapyeong & 834.4 & 62,605 & Located in the northeast of Seoul \\
\hline Goyang & 267.4 & $1,076,406$ & Located in the north of Seoul and in direct contact with Seoul \\
\hline Gwacheon & 35.9 & 61,902 & Located in the south of Seoul and in direct contact with Seoul \\
\hline Gwangmyeong & 38.5 & 308,678 & Located in the southwest of Seoul and in direct contact with Seoul \\
\hline Gwangju & 431.8 & 379,480 & Located in the southeast of Seoul \\
\hline Guri & 33.3 & 197,889 & Located in the east of Seoul and in direct contact with Seoul \\
\hline Gunpo & 36.4 & 275,508 & Located in the south of Seoul \\
\hline Gimpo & 276.6 & 458,505 & Located in the west of Seoul \\
\hline Namyangju & 460.1 & 709,881 & Located in the east of Seoul \\
\hline Dongducheon & 95.7 & 93,968 & Located in the north of Seoul \\
\hline Bucheon & 53.5 & 824,865 & Located in the east of Seoul and in direct contact with Seoul \\
\hline Seongnam & 141.8 & 940,966 & Located in the south of Seoul and in direct contact with Seoul \\
\hline Suwon & 121.1 & $1,190,074$ & Located in the south of Seoul \\
\hline
\end{tabular}


Table A1. Cont.

\begin{tabular}{cccc}
\hline City Name & Area( $\mathbf{k m}^{\mathbf{2}} \mathbf{)}$ & Population & Location and Characteristics \\
\hline Siheng & 134.4 & 489,077 & Located in the southwest of Seoul \\
Ansan & 147.1 & 653,733 & Located in the southwest of Seoul \\
Anseong & 554.1 & 186,104 & Located in the southeast of Seoul \\
Anyang & 58.5 & 554,857 & Located in the south of Seoul and in direct contact with Seoul \\
Yangju & 310.2 & 229,052 & Located in the north of Seoul \\
Yangpyeong & 877.8 & 118,372 & Located in the east of Seoul \\
Yeoju & 607.9 & 111,438 & Located in the southeast of Seoul \\
Yeoncheon & 695.3 & 43,542 & Located in the north of Seoul and on the border with North Korea \\
Osan & 42.7 & 228,718 & Located in the south of Seoul \\
Yongin & 591.5 & $1,075,659$ & Located in the southeast of Seoul \\
Uiwang & 54.0 & 162,751 & Located in the southeast of Seoul \\
Uijeongbu & 81.6 & 456,660 & Located in the northwest of Seoul and bordering North Korea \\
Icheon & 461.2 & 219,537 & Located in the southeast of Seoul \\
Paju & 672.6 & 459,158 & Located in the northwest of Seoul and bordering North Korea \\
Pyeongtaek & 452.1 & 527,166 & Located in the south of Seoul \\
Pocheon & 826.4 & 147,854 & Located in the northeast of Seoul \\
Hanam & 93.1 & 285,693 & Located in the east of Seoul and in direct contact with Seoul \\
Hwaseong & 688.1 & 842,864 & Located in the south of Seoul \\
\hline
\end{tabular}
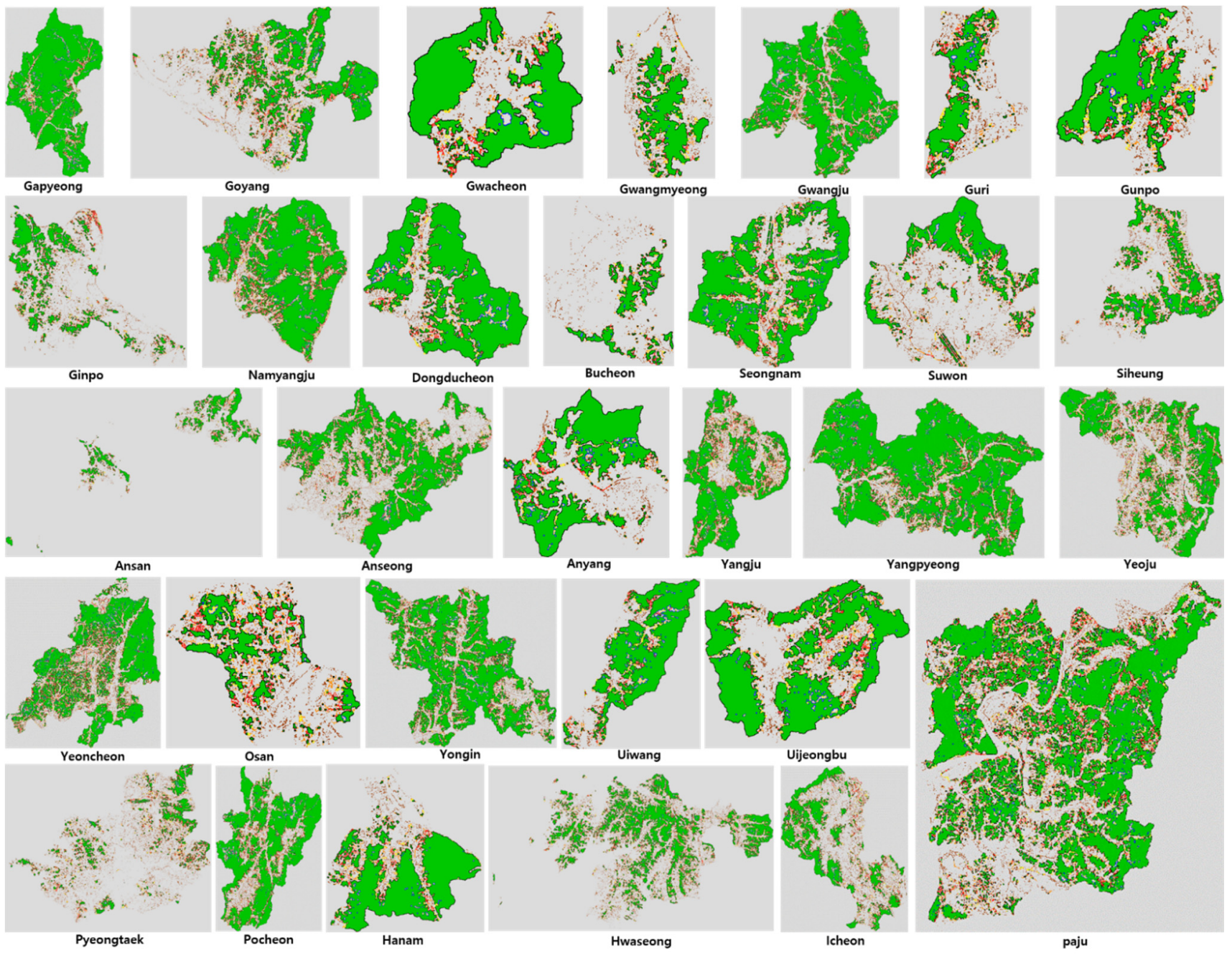

Legend
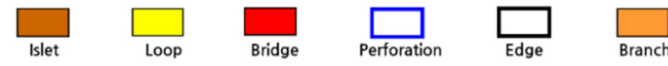

Figure A1. 1988 MSPA map of 31 cities. 


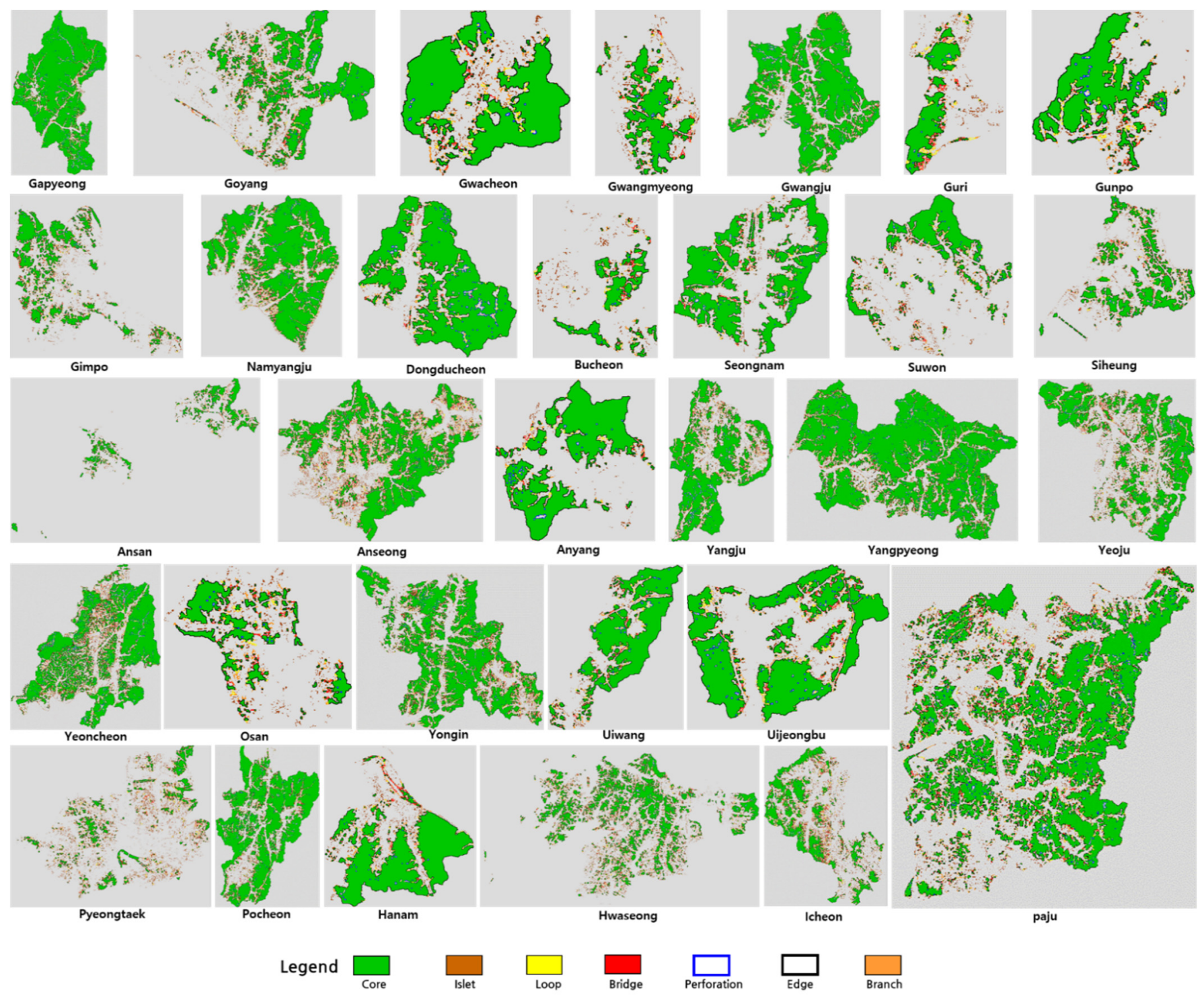

Figure A2. 2018 MSPA map of 31 cities.

\section{References}

1. Song, M.K.; Chang, H. Characterization of Cities in Seoul Metropolitan Area by Cluster Analysis. J. Korean Soc. Geospat. Inform. Syst. 2010, 18, 83-88.

2. Kim, B.S.; Yuh, H.K. A Study on Functional Features in Types of the Cities in Korea. Geogr. J. Korea 2010, 44, 537-552.

3. Kim, I.K. Socioeconomic concentration in the Seoul metropolitan area and its implications in the urbanization process of Korea. Korean J. Soc. 2010, 44, 111-128.

4. Zonneveld, I.S. The Land Unit-A Fundamental Concept in Landscape Ecology and Its Applications. Landsc. Ecol. 1989, 3, 67-86. [CrossRef]

5. Gobster, P.H. Landscape and urban planning at 100-Looking back moving forward. Landsc. Urban Plan. 2011, 100, 315-317. [CrossRef]

6. Bruns, D. Was kann Landschaftsplanung leisten? Alte und neue Funktionen der Landschaftsplanung. Nat. Landsch. 2003, 35, 114-118.

7. Wiens, J.A. Landscape ecology as a foundation for sustainable conservation. Landsc. Ecol. 2009, 24, 1053-1065. [CrossRef]

8. Thornton, D.H.; Branch, L.C.; Sunquist, M.E. The influence of landscape, patch, and within-patch factors on species presence and abundance-A review of focal patch studies. Landsc. Ecol. 2011, 26, 7-18. [CrossRef]

9. Lizee, M.H.; Manel, S.; Mauffrey, J.F.; Tatoni, T.; Cottin, M.D. Matrix configuration and patch isolation influences override the species-area relationship for urban butterfly communities. Landsc. Ecol. 2012, 27, 159-169. [CrossRef]

10. Downs, J.A.; Horner, M.W. Enhancing habitat connectivity in fragmented landscapes: Spatial modeling of wildlife crossing structures in transportation networks. Ann. Am. Assoc. Geogr. 2012, 102, 17-34. [CrossRef] 
11. Forman, R.T.; Godron, M. Patches and structural components for a landscape ecology. BioScience 1981, 31, 733-740.

12. Forman, R.T.; Alexander, L.E. Roads and their major ecological effects. Annu. Rev. Ecol. Systemat. 1998, 29, 207-231. [CrossRef]

13. Parece, T.; McGee, J.A.; Campbell, J.B. Remote Sensing with ArcGIS Pro. Virginia; Geospatial Consortium: Wayland, MA, USA, 2019.

14. Gillanders, S.N.; Coops, N.C.; Wulder, M.A. Multitemporal remote sensing of landscape dynamics and pattern change: Describing natural and anthropogenic trends. Prog. Phys. Geogr. 2008, 32, 503-528. [CrossRef]

15. Chen, Y.H. Application of GIS and remote sensing technology in the production of image map. Electron. Test. 2016, 11, 107-108.

16. Yi, L.; Zhang, G. Object-oriented remote sensing imagery classification accuracy assessment based on confusion matrix. Proc. Int. Conf. Geoinf. 2012, 10, 1109.

17. Bruzzone, L. Detection of changes in remotely-sensed images by the selective use of multi-spectral information. Int. J. Remote Sens. 1997, 18, 3883-3888. [CrossRef]

18. Griffith, J.A. Geographic techniques and recent applications of remote sensing to landscape-water quality studies. Water Air Soil Pollut. 2002, 138, 181-197. [CrossRef]

19. McGarigal, K.; Marks, B.J. FRAGSTATS: Spatial Pattern Analysis Program for Quantifying Landscape Structure; Gen. Tech. Rep. PNW-GTR-351; Department of Agriculture, Forest Service, Pacific Northwest Research Station: Portland, OR, USA, 1995.

20. Kupfer, J.A. Landscape ecology and biogeography: Rethinking land-scape metrics in a post-FRAGSTATS landscape. Prog. Phys. Geogr. Earth Environ. 2012, 36, 400-420. [CrossRef]

21. McGarigal, K.; Cushman, S.A.; Ene, E. Fragstats v4: Spatial Pattern Analysis Program for Categorical and Continuous Maps; Computer Software Program; University of Massachusetts: Amherst, MA, USA, 2012.

22. McGarigal, K. 'Fragstats Help', University of Massachusetts, Amherst. 2015. Available online: https://www.umass.edu/landeco/ research/fragstats/documents/fragstats_documents.html (accessed on 30 May 2021).

23. Mariana, B.; Barbara, R.; Luciana, G.; Rosa, L. The Extent Infrastructure Causing Fragmentation in the Hydrocarbon Basin in the Arid and Semi-Arid Zones of Patagonia (Argentina). Sustainability 2019, 11, 5956.

24. Reddy, C.S.; Sreelekshmi, S.; Jha, C.S.; Dadhwal, V.K. National Assessment of Forest Fragmentation in India: Landscape Indices as Measures of the Effects of Fragmentation and Forest Cover Change. Ecol. Eng. 2013, 60, 453-464. [CrossRef]

25. Korea Research Institute for Human Settlements. A Study on the Urban Planning Measurement by Linking between National Land Plan and Environment Plan; Korea Research Institute for Human Settlements: Anyang-si, Korea, 2015; pp. 61-85.

26. Heo, H.K.; Seong, H.C.; Lee, D.K.; Heo, M.J.; Park, J.H. A Study on Assessment Indicators for Integrated Management on Korea National Planning and Environmental Planning. J. Korean Environ. Res. Technol. 2018, 21, 27-45.

27. Heo, H.K.; Lee, D.K.; Seong, H.C.; Heo, M.J.; Park, J.H. Assessment of National and Regional Plans Using Integrated Management Index of Korea National Planning and Environmental Planning for Present Stats Evaluation. J. Korean Environ. Res. Technol. 2019, 22, 81-91.

28. de Oña, R.; López, G.; de los Rios, F.J.; de Oña, J. Cluster Analysis for Diminishing Heterogeneous Opinions of Service Quality Public Transport Passengers. Procedia Soc. Behav. Sci. 2014, 162, 459-466. [CrossRef]

29. Pirra, M.; Diana, M. Classification of Tours in the U.S. National Household Travel Survey through Clustering Techniques. J. Transp. Eng. 2016, 142, 04016021. [CrossRef]

30. Miriam, P.; Ruggero, G.P. Comparing Transport Quality Perception among Different Travelers in European Cities through Co-Cluster Analysis. Sustainability 2019, 11, 7159.

31. Wang, C.; Wang, Z.; Li, Q. Emergence of urban clustering among U.S. cities under environmental stressors. Sustain. Cities Soc. 2020, 63, 102481. [CrossRef]

32. Noiva, K.; Fernandez, J.; Wescoat, L. Cluster analysis of urban water supply and demand: Toward large-scale comparative sustainability planning. Sustain. Cities Soc. 2016, 27, 484-496. [CrossRef]

33. Jia, Y.; Tang, L.; Xu, M.; Yang, X. Landscape pattern indices for evaluating urban spatial morphology-A case study of Chinese cities. Ecol. Indicat. 2019, 99, 27-37. [CrossRef]

34. Ko, A.R.; Lim, J.W.; Kim, S.H. Classification and Characteristic Analysis of Mountain Village Landscape Using Cluster Analysis. J. Korean Soc. Rural Plan. 2020, 26, 101-112. [CrossRef]

35. Kuo, H.; Tsou, K. Modeling and Simulation of the Future Impacts of Urban Land Use Change on the Natural Environment by SLEUTH and Cluster Anlysis. Land 2018, 10, 72. [CrossRef]

36. Environmental Geographic Information Service. Available online: https:/ / egis.me.go.kr (accessed on 30 May 2021).

37. Vogiatzakis, I.N.; Mannion, A.M.; Griffiths, G.H. Mediterranean ecosystems: Problems and tools for conservation. Prog. Phys. Geogr. 2006, 30, 175-200. [CrossRef]

38. Murica, C. Edge Effects in Fragmented Forests: Implications for Conservation. Trends. Ecol. Evol. 1995, 10, 58-62.

39. McGarigal, K.; Cushman, S.A.; Neel, M.C.; Ene, E. FRAGSTATS: Spatial Pattern Analysis Program for Categorical Maps. Computer Software Program Produced by the Authors at the University of Massachusetts Amherst. 2002. Available online: https:/ / www.umass.edu/landeco/research/fragstats / fragstats.html (accessed on 7 June 2021).

40. Vogt, P.; Riitters, K. Guidos Toolbox: Universal digital image object analysis. Eur. J. Remote Sens. 2017, 50, 352-361. [CrossRef]

41. Seo, H.J.; Choi, C.H.; Lee, K.J.; Woo, D.G. Landscape Characteristics Based on Effectiveness of Wildlife Crossing Structures in South Korea. Sustainability 2021, 13, 675. [CrossRef]

42. Soille, P.; Vogt, P. Morphological segmentation of binary patterns. Pattern Recognit. Lett. 2009, 30, 456-459. [CrossRef] 
43. Ye, H.; Yang, Z.; Xu, X. Ecological Corridors Analysis Based on MSPA and MCR Model-A Case Study of the Tomur World Natural Heritage Region. Sustainability 2020, 12, 959. [CrossRef]

44. Carmen, C.V.; Romain, W.; Jeffrey, B. Clustering of European Smart Cities to Understand the Cities' Sustainability Strategies. Sustainability 2021, 13, 513.

45. Pauleit, S.; Duhme, F. Assessing the environmental performance of land cover types for urban planning. Landsc. Urban Plan. 2000, 52, 1-20. [CrossRef]

46. Lambin, E.F.; Meyfroidt, P. Land use transitions: Socio-ecological feedback versus socio-economic change. Land Use Policy 2010, 27, 108-118. [CrossRef]

47. Pauleit, S.; Ennos, R.; Golding, Y. Modeling the environmental impacts of urban land use and land cover change-A study in Merseyside, UK. Landsc. Urban Plan. 2005, 71, 295-310. [CrossRef]

48. Ding, H.Y.; Shi, W.Z. Land-use/land-cover change and its influence on surface temperature: A case study in Beijing City. Int. J. Remote Sens. 2013, 34, 5503-5517. [CrossRef]

49. Kumar, M.; Denis, D.M.; Singh, S.K.; Szabo, S.; Suryavanshi, S. Landscape Metrics for assessment of land cover change and fragmentation of a heterogeneous watershed. Int. J. Remote Sens. 2018, 10, 224-233. [CrossRef]

50. Lee, K.Y. Relationship between Physical Environment Satisfaction Neighborhood Satisfaction, and Quality of Life in Gyeonggi, Korea. Land 2021, 10, 663. [CrossRef]

51. Norris, P.E.; Rourke, M.O.; Mayer, A.S.; Halvorsen, K.E. Managing the wicked problem of transdisciplinary team formation in socio-ecological systems. Landsc. Urban Plan. 2016, 154, 115-122. [CrossRef]

52. Taylor, L.; Hochuli, D. Defining greenspace: Multiple uses across multiple disciplines. Landsc. Urban Plan. 2017, 158, 25-38. [CrossRef] 